\title{
ICT USAGE BY DISTANCE LEARNERS IN INDIA
}

\author{
Ashish Kumar AWADHIYA \\ Dr. Anshu MIGLANI \\ Assistant Director (Research \& Development) \\ Inter University Consortium (IUC) \\ Indira Gandhi National Open University, New Delhi, INDIA \\ Dr. K. GOWTHAMAN \\ Deputy Director (Training and Development) \\ Inter University Consortium (IUC) \\ Indira Gandhi National Open University, New Delhi, INDIA
}

\begin{abstract}
Open Universities across the world are embracing ICT based teaching and learning process to disseminate quality education to their learners spread across the globe. In India availability and access of ICT and learner characteristics are uneven and vary from state to state. Hence it is important to establish the facts about ICT access among learners, their ICT usage patterns and their readiness to use ICT for educational purpose. In view of this, a study was conducted with the objective to find out the access level of ICT among distance learners. The analysis indicates that maximum learners have desktop/laptops and most of them are accessing internet very frequently from their home. The analysis also indicates that maximum respondents are browsing social networking sites followed by educational and e-mail service providing websites. Findings suggest that there is a need to generate ICT based tutorials complemented with social networking tools and mobile applications. Study also shows that learners are equipped with mobile phones and they are browsing internet through it and also availing support services offered by the university. Hence possibility of integrating mobile phone services may be used for providing learner support services and content delivery.
\end{abstract}

Keywords: ICT, distance education, social media, ICT accessibility, mobile Learning.

\section{INTRODUCTION}

Information and Communication Technology (ICT) has been playing a significant role in revolutionizing higher education in general and Open and Distance Learning (ODL) in particular. ODL has been comprehended as an institutional kind of teaching learning system where learner is separated from teacher as well as peer group.

They have either no or infrequent interaction among themselves and with tutor (IGNOU, 2009). This scenario creates a feeling of isolation among learners. In such a situation the use of ICT plays a vital role by bridging the gap between learners with teachers and peers. 
ICT has significantly impacted society and education in the last two decades. With the advancement in ICT and its increasing accessibility, learners' community is now moving towards digital learning. More recently the second generation of internet tools; known as Web 2.0 tools have emerged which are changing the environment and introducing newer possibilities for education (Mc Carroll and Curran 2013). Research shows that ICT enabled education has a positive impact on teachers and learners (Christensen 2002); (Marshall and Cox, 2008). ICT also gives rise to new digital skills and competence that are needed for employment, education and training, self-development and participation in the society. ICT plays a key role to optimally utilize the human capital and potential in the society.

With the use of asynchronous and synchronous communication tools, ICT has empowered the learner community like never before. Emails, e-mail groups, online forums, webinars and web conferencing have made the learning process very flexible, where learners can learn anytime, anywhere at their own pace. Learners can now be active participants in the construction of their own learning experiences. Social Networking (SN) technologies like blogs, wikis, media-sharing services, mashups and collaborative editing tools are harnessing the "collective intelligence" of students and teachers, promoting collaboration and the sharing of knowledge (Mason \& Rennie, 2008). The websites like Facebook/Twitter/YouTube/Blogger etc can be used as a potential mode for delivering the supplementary course material and repetition of the teaching learning process (Muñoz and Towner 2009), (Griffith and Liyanage 2008).

SN sites have enabled learners to interact with each other by crossing geographical barriers and providing more learning opportunities. It has therefore given the feeling of peer to peer connectedness and learning community which can make friends, offer support to one another, exchange information and provide suggestions to deal with academic problems (Hsu and Wang, 2011).

Research has indicated that SN sites facilitate in developing feeling of social connectedness when used as a supplementary tool in teaching learning process. SN sites opened up a global platform for learners to come together and discuss among them and learn from peer to peer interaction. Not only this, SN tools have also encouraged learners to articulate opinions and have contributed towards enriching their learning experiences. It is the information-sharing feature and interactive functionality of SN sites which is relevant to education especially to distance education (Hung and Yuen, 2010).

There has been a considerable interest in the use of mobile technology in education, although the technology is still evolving (Eschenbrenner and Nah, 2007); (Ally, 2013). The global acceptance of mobile computing technologies for learning is due to incessant connectivity, compactness and portability of the device (Hsu and Ching, 2013).

Therefore it can be a promising tool to cater to the large number of learners in ODL system. As smart phones and tablets become more user-friendly and powerful, they will tend to replace desktop, laptop and notebook. It is estimated that the number of smart phones and tablets sold in 2016 will be 1.34 billion and 384 million respectively (Faille and Morrison, 2013). This presents an opportunity for educators to harness this enthusiasm for technology and utilise these resources within an educational framework. 
Many Open Universities (OU) are effectively using ICT enabled education as a tool for quality education and to bridge the gap between old and new models of teaching/learning. OUs like Open University, UK (http://www.open.ac.uk), Athabasca Open University, Canada (http://www.athabascau.ca/), Open Universities Australia (http://www.open.edu.au) etc. are adopting ICT in teaching and learning process to disseminate quality education to more and more learners spread across the world.

In India, ODL system of higher education is around $\mathbf{3 0}$ years old. At present, ODL system in India consists of Open Universities (OUs), Institutions and Universities offering distance education and also includes Correspondence Course Institutes (CCIs) in conventional dual mode universities ("Overview," 2012). Among the OUs in India, Indira Gandhi National Open University (IGNOU) is the largest and leading OU, which also falls in the category Mega University. IGNOU is catering to more than two million students in India and abroad. IGNOU has adopted various ICT tools, such as radio, television, Teleconferencing (TC) compact discs (CDs) and web-based content to cater to students (VC Report, 2013); (http://www.ignou.ac.in).

India is a developing country and availability and access of ICT are uneven and vary state to state. Also the cost of ICT and its devices are high and still a challenge for people to use it regularly especially for their study purpose. More than the availability of these technologies, issues such as geographical location, lack of knowledge and skills to use ICT, and financial constraints are major considerations in deciding what ICT to use and in what combination (IGNOU, 2010). It is therefore important to establish the facts about ICT access among learners, their ICT usage patterns and their readiness to use ICT for educational purpose. In view of the above facts, a study was conducted to access ICT usage by distance learners in order to achieve the following objectives:

$>$ To profile distance learners demographically;

$>$ To examine ICT accessibility by distance learners;

$>$ To identify the pattern and purposes of ICT usage by distance learners;

$>$ To assess the usability of university website by distance learners.

\section{METHODOLOGY}

\section{Sample}

The sample for this survey were taken from learners of IGNOU, enrolled in its three Regional Centers (RC) of Delhi which collectively constitute approximately $10 \%$ of the total students who have successfully completed their programme at IGNOU ("ViceChancellor's Report," 2013).

Design

A questionnaire was developed for the survey. This questionnaire contained Multiple Choices Questions (MCQ). MCQ based questionnaire was developed because of following reasons:

$>$ To achieve survey objectives precisely.

$>$ To reduce the duration of questionnaire administration per learner.

$>$ To receive the filled questionnaire from maximum number of learners.

$>$ To maintain the accuracy of the data from the respondents, keeping in view their short attention span. 
MCQ based questionnaire covered the following aspects of ICT:

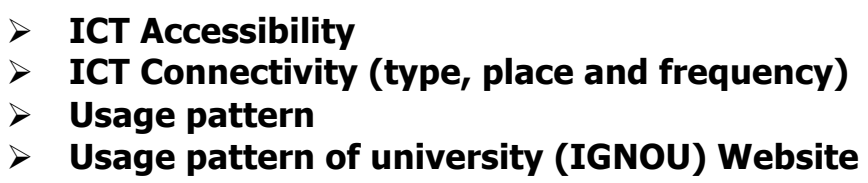

\section{Tools for Data Collection}

Hard copy of the questionnaire was distributed to $\mathbf{5 0 0}$ distance learners. Total $\mathbf{3 4 2}$ filled questionnaires were received. The data was then entered into spreadsheet and analysed.

\section{FINDINGS AND ANALYSIS}

Demographic profile

The demographic profile analysis included the following areas:

\section{Gender Classification}

Table: 1

Gender Classification

\begin{tabular}{|c|l|c|c|}
\hline S. No. & \multicolumn{1}{|c|}{ Gender } & Total & $\%$ \\
\hline 1 & Male & 192 & 57 \\
\hline 2 & Female & 142 & 42 \\
\hline 3 & Not Responded & 8 & 1 \\
\hline & Total & 342 & 100 \\
\hline
\end{tabular}

The above table (Table 3.1) indicates that out of 342 respondents, majority of the learners (57\%) were male and $42 \%$ respondents were female. Around $1 \%$ respondents did not answer this question.

Age Wise Distribution of Learners

Table: 2

Age wise Classification

\begin{tabular}{|c|l|c|c|}
\hline S. No. & \multicolumn{1}{|c|}{ Age in Years } & No. of learners & Percentage \\
\hline 1 & $<25$ & 170 & 49.7 \\
\hline 2 & $25-30$ & 100 & 29.2 \\
\hline 3 & $31-35$ & 22 & 6.4 \\
\hline 4 & $36-40$ & 14 & 4.1 \\
\hline 5 & $>40$ & 10 & 2.9 \\
\hline 6 & NA & 26 & 7.6 \\
\hline Total & 342 & 100 \\
\hline
\end{tabular}

The above table (Table: 3.2 ) indicates that out of 342 respondents, majority of the learners $(50 \%)$ were below the age of 25 years. $40 \%$ respondents belonged to age group between 25 to 40 years. Least number of respondents (3\%) was above the age of 40 years. Around $7 \%$ respondents did not provide their age. 
Table: 3

Level wise Classification

\begin{tabular}{|c|l|c|c|}
\hline S. No. & \multicolumn{1}{|c|}{ Level of the programme } & No. of learners & Percentage \\
\hline 1 & Graduate & 200 & 58.5 \\
\hline 2 & Post Graduates & 131 & 38.3 \\
\hline 3 & Others (Certificate/Diplomas) & 11 & 3.2 \\
\hline Total & 342 & 100.0 \\
\hline
\end{tabular}

The above table (Table: 3.3 ) shows that the majority of the learners $(58.5 \%)$ belonged to Graduate Level learners followed by Post Graduate (38.3\%) learners.

Mobile Users

Table: 4

Mobile users

\begin{tabular}{|c|l|c|c|}
\hline S. No. & \multicolumn{1}{|c|}{ Mobile Users } & $\begin{array}{c}\text { No. of } \\
\text { learners }\end{array}$ & Percentage \\
\hline 1 & Mobile & 335 & 98 \\
\hline 2 & Not provided & 07 & 02 \\
\hline Total & 342 & 100 \\
\hline
\end{tabular}

The above table (Table: 3.4 ) shows that $98 \%$ of respondents had mobile connection. It is inconclusive to say that remaining $2 \%$ of learners did not have any mobile connection. They might not have mentioned due to personal reasons.

\section{ICT Usages \\ Computer Device}

Table : 5

Computer Devices at Home

\begin{tabular}{|c|l|c|c|}
\hline S. No. & \multicolumn{1}{|c|}{ Computer Devices at home } & No. of learners & Percentage* \\
\hline 1 & Desktop & 170 & $50 \%$ \\
\hline 2 & Laptop & 174 & $52 \%$ \\
\hline 3 & Tablet/ iPad/ etc & 41 & $12 \%$ \\
\hline 4 & No, I don't have Computer & 22 & $7 \%$ \\
\hline
\end{tabular}

Table: 5 shows that $93 \%$ of the respondents were equipped with one or the other device (Desktop/Laptop/tablet/iPad etc.). This signifies that ICT infrastructure is not a problem for the learners. Henceforth OUs should work towards harnessing this potential. Use of laptops $(52 \%)$ was almost same in comparison to that of desktop $(50 \%)$. It may be due to its portability and compactness. Tablets/ iPads (12\%) on the other hand are still picking up the pace among learners to reach to its optimum potential. However ODL system can explore the ICT based learning through these devices in supplement with desktop and laptop. 
Table: 6

Internet Device

\begin{tabular}{|c|l|c|c|}
\hline S. No. & \multicolumn{1}{|c|}{ Internet Device } & No. of learners & Percentage* \\
\hline 1 & Data card & 113 & $34 \%$ \\
\hline 2 & Broadband & 148 & $44 \%$ \\
\hline 3 & Mobile Internet & 98 & $29 \%$ \\
\hline 4 & No, I don't have Internet Connection & 36 & $11 \%$ \\
\hline
\end{tabular}

*People may select more than one option, so percentages may add up to more than $100 \%$.

Table: 3.6 indicates that $89 \%$ of the respondents had internet connections through various modes (Datacard/ Broadband/ Mobile internet).

This means a large number of learners are digitally literate and in sync with the upcoming technologies. In this scenario it is important for IGNOU as an institution to upgrade its study material and services through these digital medium.

There is significant number of users availing mobile internet $(29 \%)$. Thus Mobiles can also be further explored in learner support and administrative services.

Place Of Internet Access

Table: 7

Place of internet access

\begin{tabular}{|c|l|c|c|}
\hline S. No. & \multicolumn{1}{|c|}{ Place of internet access } & No. of learners & Percentage* \\
\hline 1 & Home & 236 & $70 \%$ \\
\hline 2 & $\begin{array}{l}\text { Cyber cafe or other setting open to the } \\
\text { public }\end{array}$ & 60 & $18 \%$ \\
\hline 3 & Friend's home & 27 & $8 \%$ \\
\hline 4 & Regional Centers/ Study Centers & 26 & $8 \%$ \\
\hline 5 & Library & 19 & $6 \%$ \\
\hline
\end{tabular}

Table: 3. 7 , indicates that maximum (70\%) number of the respondents were accessing internet from their home. It indicates that they have opportunity to learn at their own pace and time convenient to them.

Since flexible learning at the door step is a major objective of ODL system, it is hence recommended to provide internet based learning material.

There is a need to find out a way to cater to remaining learners $(30 \%)$, who do not have constant access to internet and are dependent on one or the other place for internet access. 
Table: 8

Frequency of Internet Usage

\begin{tabular}{|c|l|c|c|}
\hline S. No. & Frequency of Internet Usage & No. of learners & Percentage* \\
\hline 1 & Daily & 244 & $73 \%$ \\
\hline 2 & Weekly & 55 & $16 \%$ \\
\hline 3 & Monthly & 25 & $7 \%$ \\
\hline 4 & Rarely & 14 & $4 \%$ \\
\hline 5 & Not at All & 4 & $1 \%$ \\
\hline
\end{tabular}

*People may select more than one option, so percentages may add up to more than $100 \%$.

Table: 3.8 indicates that $99 \%$ of the learners were accessing internet at various frequencies. Significant amount of learners (approximately $90 \%$ ) were using internet either daily or weekly.Digital literacy among learners as indicated in above tables (3.6 and 3.7) is also evident through the frequency of internet usage in this table (3.8).

\section{Computer/ Laptop Usage Pattern}

Table: 9

Computer/Laptop Usage Pattern

\begin{tabular}{|c|l|c|c|}
\hline S. No. & Computer/ Laptop Usage Pattern & No. of learners & Percentage* \\
\hline 1 & Internet surfing & 268 & $80 \%$ \\
\hline 2 & E-mail & 235 & $70 \%$ \\
\hline 3 & Downloading Audio/Video & 164 & $49 \%$ \\
\hline 4 & Word Processing & 100 & $30 \%$ \\
\hline 5 & Advanced Computing (Programming) & 76 & $23 \%$ \\
\hline 6 & Power Point & 71 & $21 \%$ \\
\hline 7 & Accounting (Excel) & 64 & $19 \%$ \\
\hline 8 & Designing & 55 & $16 \%$ \\
\hline 9 & Other & 25 & $7 \%$ \\
\hline
\end{tabular}

*People may select more than one option, so percentages may add up to more than $100 \%$.

Table: 3.9 shows that the major respondents used their Computer/ Laptop for internet surfing (80\%), checking E-mail (70\%) and downloading Audio/ Video (49\%).Learners used their device(s) more for internet based applications like e-mail, downloading Audio/ Video, rather than applications like Word Processor, Spreadsheet, and Presentations which do not need any internet connectivity. This also signifies characteristics of todays digitally empowered learners. Majority of respondents, who used Advanced Computing and Designing, belonged to Computer Application programmes. 
Table: 10

Internet Usage Pattern

\begin{tabular}{|c|l|c|c|}
\hline S.No. & \multicolumn{1}{|c|}{ Purpose of Internet Usage } & No. of learners & Percentage* \\
\hline 1 & $\begin{array}{l}\text { Social Networking } \\
\text { (Facebook/Twitter/YouTube/Blog etc) }\end{array}$ & 269 & $80 \%$ \\
\hline 2 & Educational/ College sites & 234 & $70 \%$ \\
\hline 3 & E-mail access & 200 & $60 \%$ \\
\hline 4 & News & 135 & $40 \%$ \\
\hline 5 & Music/Film/Celebrity & 117 & $35 \%$ \\
\hline 6 & Sports & 87 & $26 \%$ \\
\hline 7 & Games & $\mathbf{8 0}$ & $24 \%$ \\
\hline 8 & Religion & 7 & $14 \%$ \\
\hline 9 & Other & $2 \%$ \\
\hline
\end{tabular}

Table: 3.10 indicates that maximum number $(80 \%)$ of respondents were using social networking sites followed by browsing Educational/ College sites $(\mathbf{7 0} \%)$ and accessed email $(60 \%)$. Thus these sites can be exploited for teaching and learning purposes.

Interestingly $\mathbf{7 0} \%$ respondents' accessed educational websites, hence educational institute may host their teaching learning material on their website.

Visit To University (IGNOU) Website

Table 11:

Visit to IGNOU website

\begin{tabular}{|c|c|c|c|}
\hline S.No. & Visit to IGNOU website & No. of learners & Percentage \\
\hline 1 & Yes & 311 & $91 \%$ \\
\hline 2 & No & 14 & $4 \%$ \\
\hline \multirow[t]{2}{*}{3} & NA & 17 & $5 \%$ \\
\hline & Total & 342 & $100 \%$ \\
\hline
\end{tabular}

Table: 11 indicates that significant number of respondents $(91 \%)$ were visiting IGNOU website for various purposes. This is very positive indicator which reflects learners' interest towards ICT based learning opportunities. 
Table 12

Usage Pattern of IGNOU Website

\begin{tabular}{|c|l|c|c|}
\hline S. No. & \multicolumn{1}{|c|}{ Usage Pattern of IGNOU Website } & $\begin{array}{c}\text { No. of } \\
\text { learners }\end{array}$ & Percentage* \\
\hline 1 & Checking Results & 287 & $87 \%$ \\
\hline 2 & Downloading Assignments & 198 & $60 \%$ \\
\hline 3 & Downloading Exam form & 198 & $60 \%$ \\
\hline 4 & Online Registration & 153 & $46 \%$ \\
\hline 5 & Downloading Course material & 103 & $31 \%$ \\
\hline 6 & Checking RC Information & 99 & $30 \%$ \\
\hline 7 & Viewing Faculty Information & 27 & $16 \%$ \\
\hline 8 & Using Broadcast/ Video & $8 \%$ \\
\hline
\end{tabular}

Table: 12 indicates that maximum number of respondents (87\%) visited IGNOU website for checking results, followed by downloading assignments $(60 \%)$ and examination forms $(60 \%)$.

The table indicates very less usages of Broadcast/Video (8\%) in comparison to other uses. The reason behind this pattern can be assumed to be related to lack of awareness, low band width or it may be explored by further studies.

SMS Alert Services of University (IGNOU)

Table: 13

Use of SMS Alert Services

\begin{tabular}{|c|cc|c|c|}
\hline \multicolumn{3}{|c|}{ SMS Alert } & No. of learners & Percentage \\
\hline S. No. & & 202 & $59 \%$ \\
\hline 1 & Yes & 129 & $38 \%$ \\
\hline 2 & No & 11 & $3 \%$ \\
\hline 3 & NA & Total & 342 & $100 \%$ \\
\hline & & &
\end{tabular}

Table: 13 indicates that significant numbers of respondents (59\%) availed SMS alert services of IGNOU. This is a very good indicator of showing learners interest towards availing mobile based support services. However this percentage can be enhanced through increasing awareness among learners. Also the mobile based learning can be explored further. 


\section{DISCUSSION AND CONCLUSION}

Most of the learners were equipped with one or more computer devices; hence ICT infrastructure is not a problem for them. They are digitally literate and in sync with the upcoming technologies. Learners have inclination towards using internet based applications like e-mail, downloading Audio/Video, rather than applications like word processing, spreadsheet and presentations which do not need any internet connectivity. Similar finding were also reported by Khan et al., 2011. Respondents actively used social networking and educational websites for connecting to people and gathering information. This survey also indicated that majority $(\approx 80 \%)$ of the respondents were below 30 years of age. It is important to cater to this large number of learners' population through ICT based quality educational opportunities to attract more and more learners and survive in the global competition. Therefore, there is a need to generate ICT based tutorials and complement them with social media tools for learning and teaching process.

Learners' had access to internet facility mostly at their homes which gave them the opportunity to learn at their own pace and time convenient to them. However, there were also significant percentages of learners who did not have constant access to internet and are dependent on one or the other place for the same.

IGNOU website was being visited by large number of learners for administrative reasons varying from-Result, Assignments, Exam forms, and Registration etc. opportunities. However, it was less explored for academic purposes like Course material download, Broadcast/ Video etc. The reason behind this pattern could be assumed to be related to lack awareness, requirement of high speed internet, or it may be explored by further studies.

Almost every one among the respondents had mobile connections and SMS alert services of IGNOU were also quite popular among them. This indicator reflected learner's interest towards availing mobile based support services. Also the mobile based supplementary study material may be explored further. These findings are supported by Kumar et al., 2011 which concludes that learners had positive inclination towards use of mobile phones for learner support services, content delivery and communication among peers.

Nevertheless, it should also be considered that the sample size of our respondents belonged to Delhi RCs which is located in the metropolitan city. So, the results may not be generalized for rest of the country. There is a further scope to conduct a nationwide study to explore ICT usages by distance learners for holistic perspective.

\section{BIODATA and CONTACT ADDRESSES of the AUTHORS}

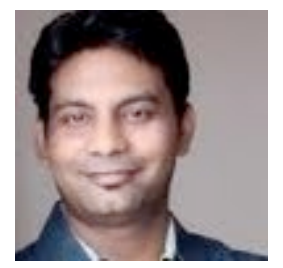

Ashish K. AWADHIYA is working as Asst. Director (Training and Development), at Inter University Consortium (IUC), IGNOU. He has done Masters in Life Science and Distance Education. He has experience in Employee Training Management System, Developing and Coordinating Online Trainings and Training Need Assessment. He is a Trainer in the areas of Social Media Learning, Computer Added Learning, Clinical Research and Clinical Quality Assurance. 
Ashish Kumar AWADHIYA

Assistant Director (Training and Development),

Inter University Consortium (IUC),

Indira Gandhi National Open University (IGNOU),

New Delhi-110068, India

Phone +91-11-2957-2316,

Fax: +011-2953-1001

Email: akawadhiya@ignou.ac.in

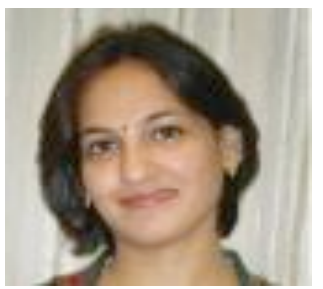

Dr. Anshu MIGLANI is working as Assistant Director (R\&D), Inter University Consortium (IUC), IGNOU. Her specializations are GIS, Remote Sensing, Hyperspectral image processing, and Geospatial applications in Natural Resources Management. Presently she is involved in Research and Development and Training in the field of ICT implementation in Distance Education.

Dr. Anshu MIGLANI

Assistant Director (Research \& Development)

Inter University Consortium (IUC)

Indira Gandhi National Open University (IGNOU)

New Delhi-110068, India.

Phone +91-11-2957-2319

Fax: +91-11-2953-1001

Email: anshu.miglani@ignou.ac.in

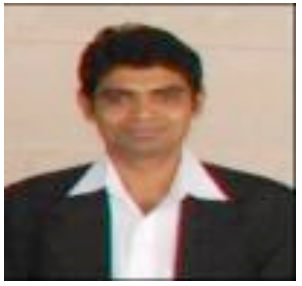

K. GOWTHAMAN is currently working as Deputy Director (T\&D), Inter University Consortium (IUC), IGNOU. He has 17 years of industry experience in Software Application Development, Maintenance and Support activities. His specializations are Management Information System, Software Engineering, Multimedia Application Development, Improving Quality Process, Re-Engineering and Reverse Engineering.

Dr. K. GOWTHAMAN

Deputy Director (Training and Development),

Inter University Consortium (IUC),

Indira Gandhi National Open University (IGNOU)

New Delhi-110068, India.

Phone +91-11-2957-2317

Fax: +91-11-2953-1001

Email: gowthaman@ignou.ac.in

\section{REFERENCES}

Christensen, R. (2002). Effects of Technology Integration Education on the Attitudes of Teachers and Students. Journal of Research on technology in Education, 34(4).

Eschenbrenner, B. \& Nah, F. F. H. (2007). Mobile technology in education: uses and benefits. International Journal of Mobile Learning and Organisation,1(2), 159-183. 
Griffith, S., \& Liyanage, L. (2008, June). An introduction to the potential of social networking sites in education. In Emerging Technologies Conference 2008 (p. 9).

Hsu, Y. C., \& Ching, Y. H. (2013). Mobile App Design for Teaching and Learning: Educators' Experiences in an Online Graduate Course. International Review of Research in Open \& Distance Learning, 14(4).

IGNOU, 2010. Communication Networks, MDE-411, Education Communication Technologies, New Delhi, STRIDE, IGNOU, 37.

IGNOU, 2009. Defining Distance Education, ES-311, Growth and Philosophy of Distance Education, New Delhi: STRIDE, IGNOU, 19.

Khan, S. A., Bhatti, R. \& Ahmad Khan, A. (2011). Use of ICT by Students: A Survey of Faculty of Education at IUB.

Kumar, L. S., Jamatia, B., Aggarwal, A. K. \& Kannan, S. (2011). Mobile Device Intervention for Student Support Services in Distance Education Context--FRAME Model Perspective. European Journal of Open, Distance and E-Learning.

Marshall, G., \& Cox, M. J. (2008). Research methods: Their design, applicability and reliability. In International handbook of information technology in primary and secondary education (pp. 983-1002). Springer US.

Mason, R. \& Rennie, F. (2008). E-learning and social networking handbook: Resources for higher education (1st ed.). New York, NY: Routledge.

Mc Carroll, N. \& Curran, K. (2013). Social Networking in Education.International Journal of Innovation in the Digital Economy $, 4(1), 1-15$.

Overview. (2012). Retrieved February 18, 2014, from http://mhrd.gov.in/overviewdl Vice-Chancellor's Report, (2013). 26th Convocation of IGNOU, New Delhi. 